\title{
A record of Holocene climate in the mineral magnetic record of Alpine lakes: Sägistalsee and Hinterburgsee
}

\author{
L. Lanci ${ }^{\mathrm{a}, *}$, A.M. Hirt ${ }^{\mathrm{a}}$, A.F. Lotter $^{\mathrm{b}}$, M. Sturm ${ }^{\mathrm{c}}$ \\ a Institute of Geophysics, ETH Hönggerberg, CH-8093 Zurich, Switzerland \\ b Laboratorium voor Palaeobotanie en Palynologie, Universiteit Utrecht, 3584 CD Utrecht, The Netherlands \\ c Environmental Physics, EAWAG-ETH, CH-8600 Dübendorf, Switzerland
}

Received 6 October 2000; received in revised form 8 January 2001; accepted 21 February 2001

\begin{abstract}
The effect of climate variations on the magnetic properties of sediments from two small Alpine lakes in the Bernese Alps, Switzerland was investigated. Although relatively similar in water volume and general environment, Sägistalsee and Hinterburgsee have different catchment vegetation and lithology due to their different elevation and geographic locations. The climatic signal in the mineral magnetic parameters of the sediments was validated and interpreted with the aid of palynological and geochemical data. The sediment age was determined with several accelerated mass spectrometry ${ }^{14} \mathrm{C}$ dates. The results from the different lakes compare well on a common time scale and show that the influence of local conditions on the magnetic record is rather small. A climatic influence on the mineral magnetism has been recognized at both studied sites. This is interpreted as a consequence of the production of an authigenic mineral with particularly uniform magnetic properties during the warmer stages and the influx of heterogeneous detrital magnetic minerals during the colder stages. The clearest climate record is found in sediments with no organic matter whereas the anoxic conditions found in highly organic sediment can completely obliterate the climate signal recorded in the sediment magnetic properties. (C) 2001 Elsevier Science B.V. All rights reserved.
\end{abstract}

Keywords: magnetic properties; lake sediments; paleomagnetism; Holocene; climate change; alpine environment

\section{Introduction}

Alpine lakes are particularly sensitive to climate variations because of their location and distinct characteristics, such as small water volume and long ice-cover [1,2]. Moreover, their sedimentary record represents a unique environmental archive

\footnotetext{
* Corresponding author. Present address: Department of Geological Sciences, Rutgers University, 610 Taylor Road, Piscataway, NJ 08854-8066, USA. Fax: +1-732-445-3745; E-mail: lluca@rci.rutgers.edu
}

for the past climate change in the Alps. For this reason they can provide valuable records of late Quaternary continental climatic and environmental variability (e.g. [2-6]) and they represent ideal sites for detailed climate studies. Magnetic properties offer an attractive tool to investigate the sedimentary record of climate change (e.g. [712]). It has been demonstrated that magnetic properties are a very effective climatic proxy in a similar Alpine site (Bachalpsee) $[13,14]$ and do not suffer from the long response time of the pollen assemblages, which make them poor indicators for short, abrupt climatic changes. 
In this paper we investigate the sediment magnetic properties of two Alpine lakes from the same region to explore how local environmental constraints influence the magnetic signal. Two sediment cores were sampled at Sägistalsee and Hinterburgsee sites, hereafter referred to as SAEG and HIN, respectively. The cores were taken as part of the AQUAREAL project [14], using a modified Livingstone piston corer with a procedure described by Merkt and Streif [15]. The aim of the paper is to show that the sediment magnetic properties in Alpine lakes can provide a detailed and robust record of the climate changes. Moreover, we validate previous results from nearby Bachalpsee and discuss the differences in the climate record due to the local characteristic of the lakes.

\section{Environmental setting}

The studied sites are small lakes located in the Bernese Alps, Switzerland (Fig. 1). The SAEG and the HIN are similar in water volume and general environment (i.e., Alpine), mainly differing in catchment vegetation and lithology due to their slightly different elevation and geographic locations. SAEG is located at an altitude of $1935 \mathrm{~m}$ asl, has a water depth of $9.7 \mathrm{~m}$, a surface area of $0.07 \mathrm{~km}^{2}$ and its hydrological catchment has an area of $3.85 \mathrm{~km}^{2}$. HIN's altitude is $1514 \mathrm{~m}$ asl, with a surface area of about $0.05 \mathrm{~km}^{2}$ and maximum water depth of $11.1 \mathrm{~m}$. The area of its catchment basin covers $1.62 \mathrm{~km}^{2}$.

\subsection{Palynological and paleoecological data}

Aside from the magnetic properties, climate information at these sites is provided by analysis of the pollen ([16] and Wick and Lotter, personal communication), chironomids [17], plant macrofossils ([18] and Wick and Lotter, personal communication) and geochemical analyses $[19,20]$. These environmental proxies give us general information on climate; it is not possible to gather direct information on paleoprecipitation and icecover but it is generally believed that warm periods have higher precipitation while cold periods are dry. Ice-cover on the lakes is possibly longer during cold periods. The pollen assemblages set the framework for the interpretation of climate changes in both studied sites. The results of the pollen analyses (Fig. 3) are summarized as the first detrended correspondence analysis (DCA)

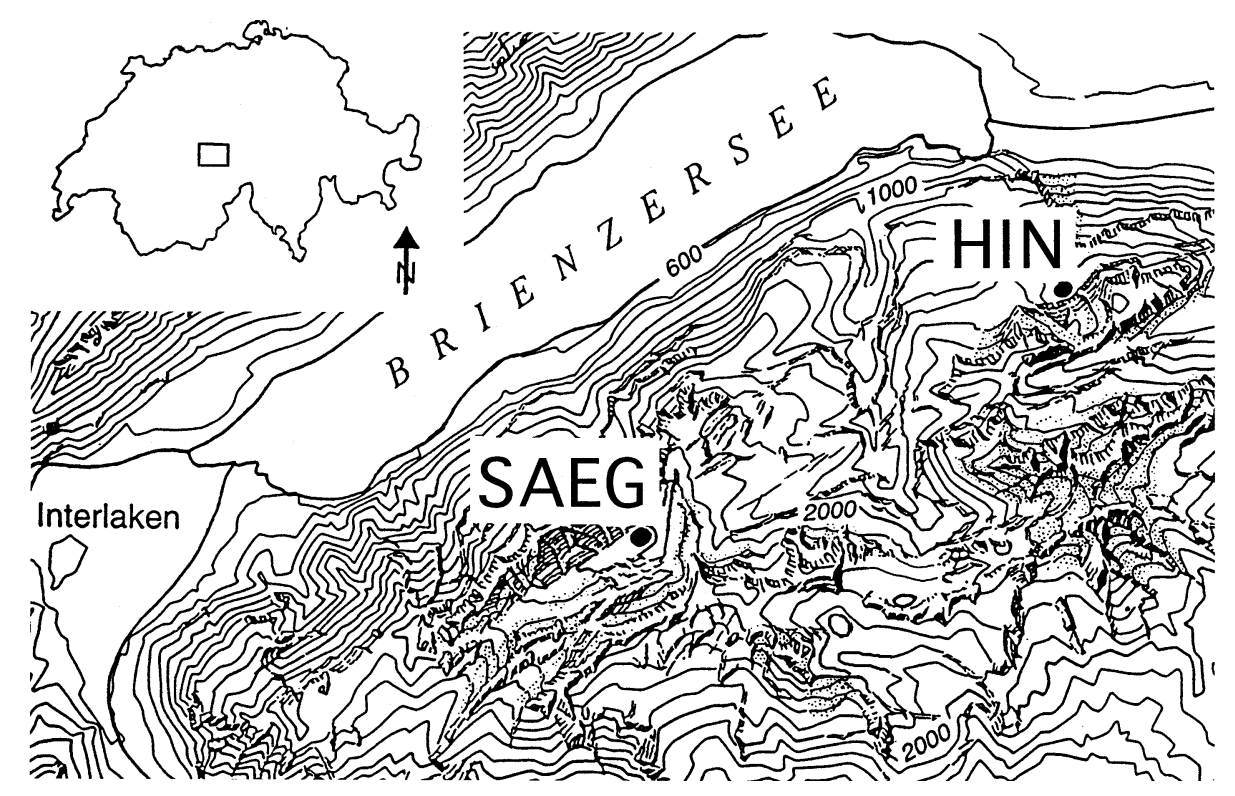

Fig. 1. Location map of the SAEG and HIN. 
axis [21] carried out using the CANOCO program [22].

Plant macrofossil remains from the SAEG site suggest that most of the tree pollen in SAEG results from long distance transport. Sparse Pinus cembra (Swiss stone pine) stands dominated the vegetation before Abies alba (fir) migrated into the catchment at about $8000 \mathrm{cal}$ BP. This rather open vegetation was gradually replaced by Picea abies (spruce) forests beginning around $6500 \mathrm{cal}$ BP. Forest clearance during the Bronze Age which began around 4500 cal BP led to an opening of the forest cover. Medieval forest clearance resulted in a second anthropogenic lowering of the tree line at SAEG. It is only during the last century that the tree line, which is now at about $1900 \mathrm{~m}$, reached the lake again.

Pollen and plant macrofossil analyses at HIN show that the catchment vegetation was open during the late-glacial period, most probably with no trees locally present. At the onset of the Holocene, $P$. cembra spread and dominated the vegetation for about $4000 \mathrm{yr}$, before $A$. alba migrated into the catchment around 7500 cal BP. Around 6500 cal BP P. abies spread and subsequently replaced the open Swiss stone pine and fir forest. Spruce dominates the forest still today.

At both sites the abundance of Alpine herbs (Gramineae and Plantago alpina) found near the core top indicates an increase of local grazing.

\subsection{Age models and sedimentology}

Sediment chronology is based on calibrated accelerated mass spectrometry (AMS) ${ }^{14} \mathrm{C}$ dating and, to a lesser extent, on known pollen events [2]. In particular in the HIN core, pollen is used to extend dating at the core bottom where organic matter suitable for ${ }^{14} \mathrm{C}$ dating was not available. The depth-age models are shown in Fig. 2a,b.

Radiocarbon results for the SAEG core are coherent and the sedimentation rate varies smoothly from the top to the core bottom, which is dated at about 9000 cal BP. Sedimentation rate decreases from about $2.5 \mathrm{~mm} / \mathrm{yr}$ in the core bottom, below $1000 \mathrm{~cm}$ core depth, to an almost constant 1.2 $\mathrm{mm} / \mathrm{yr}$ in the top $800-900 \mathrm{~cm}$ of the core (Fig. 2a).

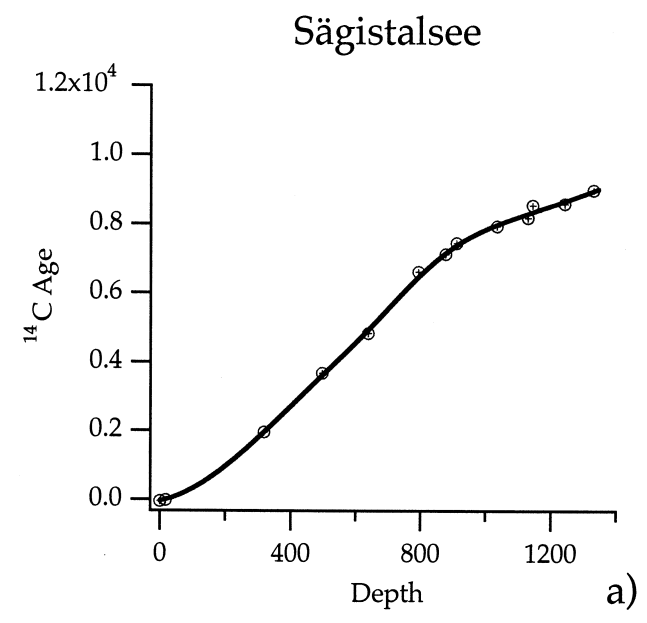

Hinterburgsee

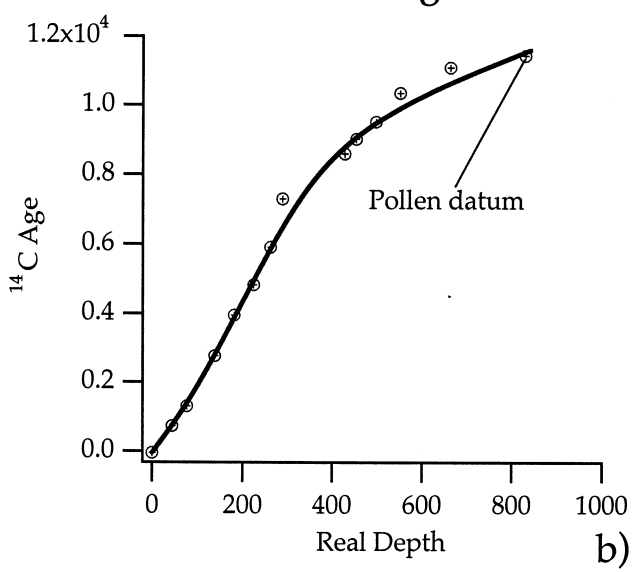

Fig. 2. Depth-age model for the SAEG (a) and the HIN (b). The data points are AMS ${ }^{14} \mathrm{C}$ dates, except for the labeled point in (b) that represents the estimated age for the Holocene/Pleistocene boundary based on the pollen assemblage. The vertical axis is in calibrated ${ }^{14} \mathrm{C}$ years before 1950 (present), depth is in $\mathrm{cm}$ from the core top. In the HIN core the sediment depth was recalculated by removing the thickness of the turbidite beds as described in the text.

Several AMS dated samples are available in the HIN core above $800 \mathrm{~cm}$ depth, a few specimens that gave too old dates compared to adjacent samples or that originated from turbidites were discarded in the construction of the depth-age model. Turbidites and slump deposits constitute a significant part (about $30 \%$ or a total of 466 $\mathrm{cm}$ ) of the entire length of the HIN core. Due to this large amount, their non-uniform distribu- 


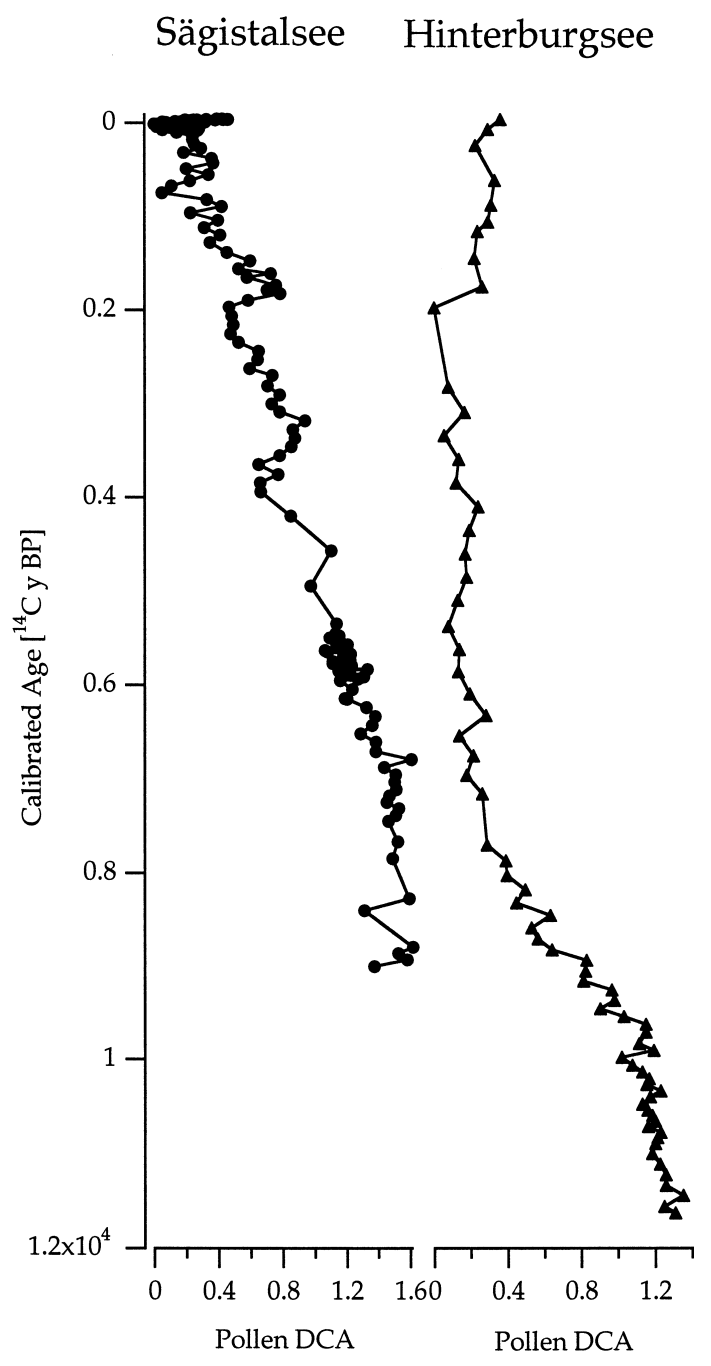

Fig. 3. DCA of the pollen data from SAEG and HIN. The figure shows the main trend of variation in the pollen assemblages and thus represents the major variations in the regional terrestrial vegetation.

tion, and the fact that these sediments were deposited almost instantaneously, the turbiditic and slump deposits were excluded from the sediment column when constructing the depth-age model. We refer to the depth without the turbidites as real-depth. In the HIN core a noted change in the pollen assemblages (Fig. 3), which is associated with the Younger Dryas cold stage, occurs at approximately $800 \mathrm{~cm}$ real-depth; following [2] we give this event a conventional age of 11500 cal BP. The age at the core bottom is undetermined, moreover, the core sections below 1280 $\mathrm{cm}$ depth could not be lithologically correlated with the section above, and their actual depth is somewhat uncertain. This lower part of the core was discarded when interpreting the climatic record. A change in sedimentation rate from 1.60 to $0.65 \mathrm{~mm} / \mathrm{yr}$ occurs at about $500 \mathrm{~cm}$ depth from the core top, this corresponds to 1.20 and 0.45 $\mathrm{mm} / \mathrm{yr}$, respectively, at $400 \mathrm{~cm}$ in real-depth as depicted in Fig. 2. The change in sedimentation rate marks a transition in the sedimentation style that goes from mostly clastic to organic. The high content of organic matter above $500 \mathrm{~cm}$ depth creates an anoxic environment in the sediment that has profound consequences on its magnetic properties.

\section{Sediment magnetic results}

Samples for magnetic analyses were collected from the SAEG and HIN cores with a $2 \mathrm{~cm}$ interval and sealed in $3.4 \mathrm{~cm}^{3}$ cylindrical plastic boxes. To prevent sediments from drying and, as far as possible, from undergoing chemical changes, they were stored at $4^{\circ} \mathrm{C}$. A total of 650 samples from SAEG and 732 samples from HIN were measured, corresponding to an average sampling rate of approximately $15 \mathrm{yr}$ in both the cores. The wet samples were weighed and the magnetization and the susceptibility expressed in mass units.

\subsection{Magnetic mineralogy}

The magnetic mineralogy of selected samples was investigated using the acquisition of isothermal remanent magnetization (IRM) and thermal demagnetization of orthogonal IRMs [23]. In the SAEG core we used stepwise IRM acquisition up to a maximum field of $1 \mathrm{~T}$ (Fig. 4a). A characteristic magnetic phase with a rather uniform coercivity spectrum, showing saturation at about 150 $\mathrm{mT}$ was found in all the samples. In addition to the low-coercivity phase, the samples taken from the bottom of the core have a variable contribution from a high-coercivity mineral that does not 

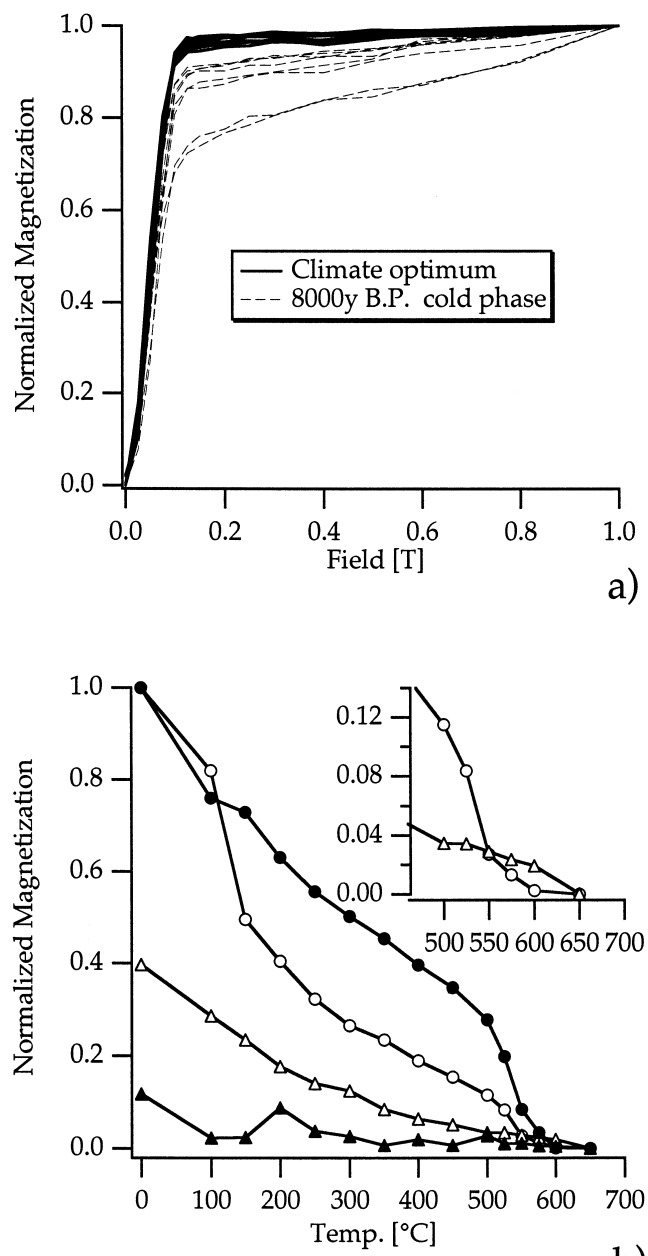

b)

Fig. 4. IRM acquisition (a) and thermal demagnetization of orthogonal components (b) in SAEG sediments, in which the triangles represent the component with coercivity $>150 \mathrm{mT}$ and circles the component with coercivity $\leq 150 \mathrm{mT}$ in this and Fig. 5. Open and filled symbols are measurements from sample A2100-66, characteristic of cold stages, and sample B1950-51, characteristic of warm stages, respectively. The insert is an enlarged plot of sample A2100-66 showing that the magnetic phase with high coercivity has an unblocking temperature exceeding $600^{\circ} \mathrm{C}$.

saturate by $1 \mathrm{~T}$. Isothermal magnetization was imparted with a $1 \mathrm{~T}$ field along the sample $Z$ axis and $150 \mathrm{mT}$ along the sample $X$-axis before thermal demagnetization, and typical results are shown in Fig. 4b. In samples in which the highcoercivity phase is low or absent, such as B195051, the IRM lies along the $X$-axis, and has an unblocking temperature around $575^{\circ} \mathrm{C}$. This indicates that the magnetization is carried by magnetite. In samples with a larger high-coercivity phase, such as A2100-66, the IRM is a composite of two components. The low-coercivity component has an unblocking temperature between 550 and $575^{\circ} \mathrm{C}$, indicative of magnetite, and the high-coercivity component exceeds $600^{\circ} \mathrm{C}$. This suggests

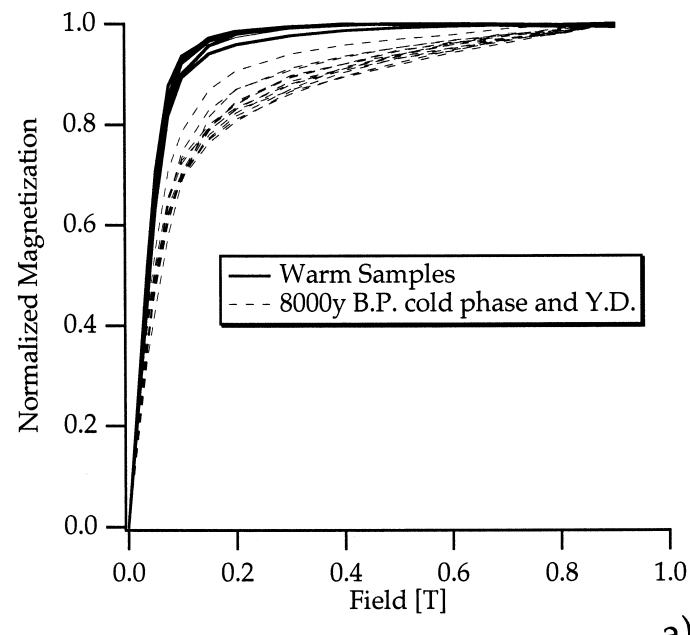

a)

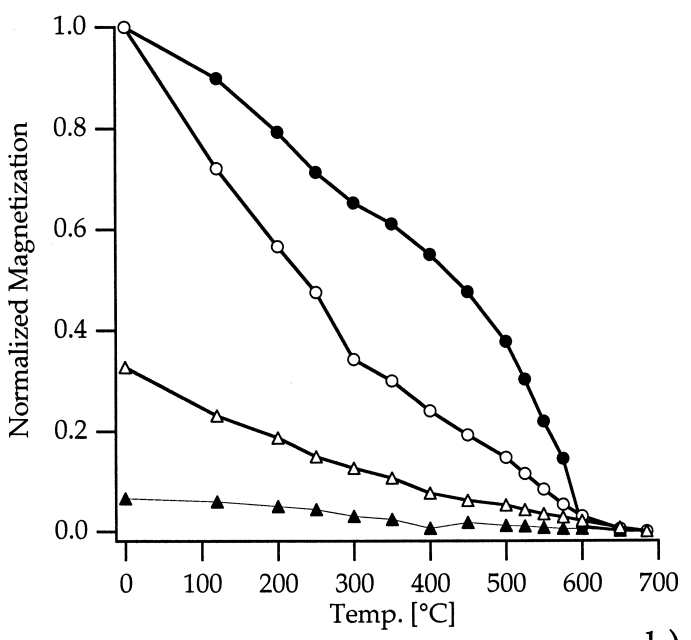

b)

Fig. 5. IRM acquisition (a) and thermal demagnetization of orthogonal components (b) in HIN sediments. Triangles represent the high-coercivity component $(>150 \mathrm{mT})$ and circles represent the component with coercivity $\leq 150 \mathrm{mT}$. Open and filled symbols are measurements from sample 72150-70, characteristic of glacial stages, and sample 62200-12, characteristic of interglacial (warm) stages, respectively. 
that the main carrier of the high-coercivity phase is hematite.

IRM acquisition curves in the HIN samples (Fig. 5a) have a similar behavior to the SAEG samples. For practical reasons a field of $1 \mathrm{~T}$ was first applied in the $-Z$ direction in the HIN samples and subsequent increasing fields up to a maximum of $1 \mathrm{~T}$ in the $+Z$ direction. The results of this backfield IRM acquisition were then normalized between zero and the maximum magnetization for a better comparison with the SAEG results. A magnetic mineral with a maximum coercivity of about $150-200 \mathrm{mT}$ and a rather uniform coercivity spectrum is found along the whole core. In samples taken from specific depth intervals (e.g., Younger Dryas) this signal is superimposed with a high-coercivity phase that does not saturate at $1 \mathrm{~T}$. The thermal demagnetization of a composite IRM with orthogonal fields of $150 \mathrm{mT}$ and $1 \mathrm{~T}$ is shown in Fig. 5b for two typical samples. Sample 72150-70, taken in the Younger Dryas section is representative of the mineralogy of glacial samples in the HIN core. It shows a large high-coercivity phase and unblocking temperature exceeding $600^{\circ} \mathrm{C}$ suggesting the presence of hematite in addition to another low-coercivity mineral. Sample 62200-12, representative of the non-glacial section of the core, has an unblocking temperature of the low-coercivity phase $(\leq 150$ $\mathrm{mT}$ ) between 575 and $600^{\circ} \mathrm{C}$ and a negligible high-coercivity phase. We interpret this result to show that magnetite is the main magnetic carrier in samples from the warm Holocene stage. No evidence for a significant amount of greigite or other magnetic sulfide was found in the measured samples of either site.
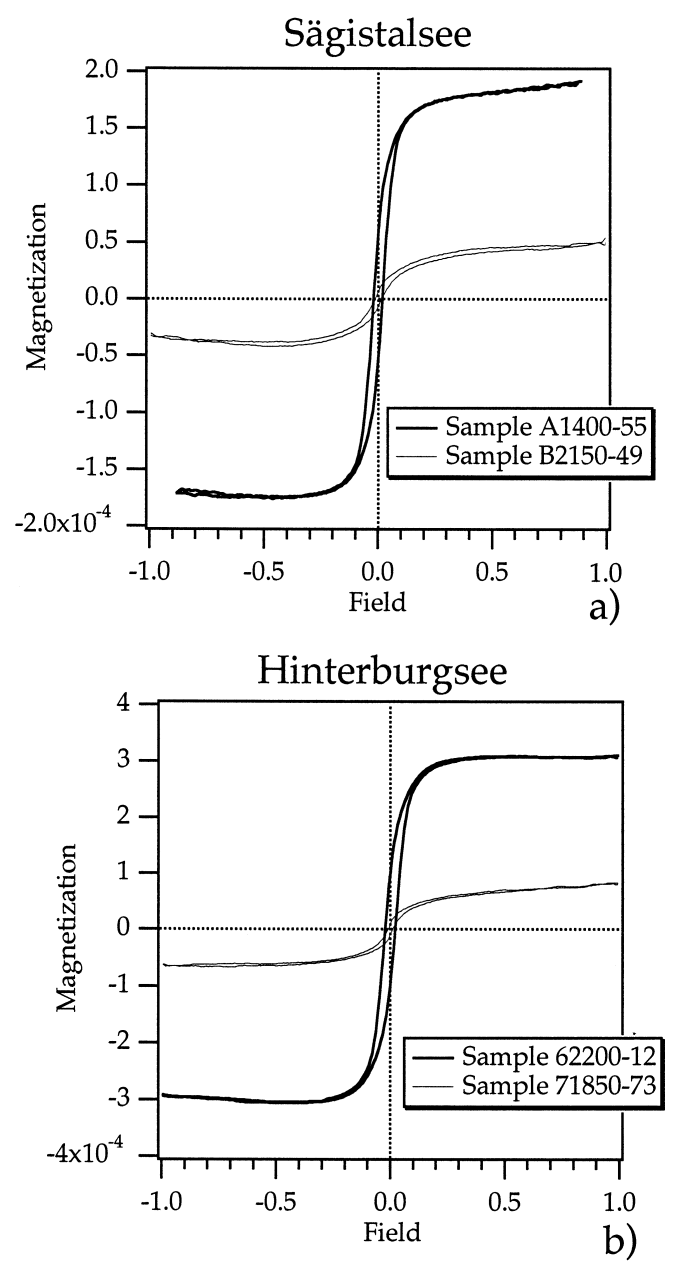

Fig. 6. Hysteresis loops after the removal of the paramagnetic component of the magnetization of typical samples from SAEG and HIN cores. Loops drawn with the thin and thick lines are taken from the 'cold/dry' and 'warm/humid' part of the cores, respectively. The magnetization is in mass units $\left(\mathrm{A} \mathrm{m} \mathrm{m}^{2} / \mathrm{kg}\right)$ and the field is in $\mathrm{T}$.

Table 1

Mean values and standard deviation of the principal magnetic parameter in the Alpine lakes

\begin{tabular}{llll}
\hline Data & $\begin{array}{l}\text { Hinterburgsee } \\
(450-1280 \mathrm{~cm})\end{array}$ & $\begin{array}{l}\text { Sägistalsee } \\
(\text { whole core })\end{array}$ & $\begin{array}{l}\text { Bachalpsee } \\
(0-700 \mathrm{~cm})\end{array}$ \\
\hline$\chi_{\mathrm{HiField}}\left(\mathrm{m}^{3} / \mathrm{kg}\right)$ & $3.90 \times 10^{-8} \pm 1.85 \times 10^{-8}$ & $4.12 \times 10^{-8} \pm 1.49 \times 10^{-8}$ & $4.40 \times 10^{-8} \pm 1.29 \times 10^{-8}$ \\
$\chi\left(\mathrm{m}^{3} / \mathrm{kg}\right)$ & $5.30 \times 10^{-8} \pm 1.64 \times 10^{-8}$ & $5.50 \times 10^{-8} \pm 8.59 \times 10^{-9}$ & $5.77 \times 10^{-8} \pm 1.55 \times 10^{-8}$ \\
$\mathrm{IRM}_{1 \mathrm{~T}}\left(\mathrm{~A} \mathrm{~m} \mathrm{~m} \mathrm{~m}^{2} / \mathrm{kg}\right)$ & $2.93 \times 10^{-4} \pm 2.95 \times 10^{-4}$ & $5.89 \times 10^{-4} \pm 3.57 \times 10^{-4}$ & $6.59 \times 10^{-4} \pm 3.51 \times 10^{-4}$ \\
$\mathrm{ARM}\left(\mathrm{A} \mathrm{m}{ }^{2} / \mathrm{kg}\right)$ & $1.76 \times 10^{-5} \pm 1.75 \times 10^{-5}$ & $3.83 \times 10^{-5} \pm 2.66 \times 10^{-5}$ & - \\
$H_{\mathrm{c}} / H_{\mathrm{cr}}$ & $2.78 \pm 0.95$ & $2.18 \pm 0.60$ & $2.15 \pm 0.41$ \\
$M_{\mathrm{s}} / M_{\mathrm{rs}}$ & $0.20 \pm 0.061$ & $0.26 \pm 0.063$ & $0.26 \pm 0.062$ \\
$c$-ratio & $0.80 \pm 0.18$ & $0.93 \pm 0.096$ & $0.92 \pm 0.070$ \\
$t$-ratio & $0.69 \pm 0.10$ & $0.57 \pm 0.18$ & $0.87 \pm 0.051$ \\
\hline
\end{tabular}




\subsection{Hysteresis properties}

Magnetic hysteresis was measured on a subset of 149 samples from the SAEG core and 129 samples from the HIN core using an alternating gradient field magnetometer. The hysteresis loops from the two cores are remarkably similar (Fig. 6 and Table 1) and in general confirm the results from the IRM experiments. They show either a single low-coercivity mineral, with a maximum coercivity of $100-150 \mathrm{mT}$ or a mixture of lowand high-coercivity minerals. In this latter case, the mass magnetization is several times smaller and the loop is not closed at the maximum field of $1 \mathrm{~T}$.

The hysteresis parameters $\left(H_{\mathrm{c}} / H_{\mathrm{cr}}\right.$ and $\left.M_{\mathrm{s}} / M_{\mathrm{rs}}\right)$, calculated after removal of the paramagnetic component of the magnetization, are plotted on a Day graph [24] in Fig. 7a,b. Samples from different core sections are plotted with different symbols to show their systematic clustering according to the interpreted climatic stages. In the HIN (Fig. $7 b)$ we also differentiate between the sedimentation styles. Because of the mixed magnetic mineralogy in the samples with a high-coercivity phase the hysteresis parameters are not interpreted as being due to grain size variations. Nevertheless they clearly show the different behavior between warm and cold climatic stages as well as the similarity of the magnetic properties between the two studied sites. The paramagnetic component of the magnetization was computed from the high-field rectilinear part of loops and it is found to be always very large. The mean high-field susceptibility $\left(\chi_{\text {HiField }}\right)$ in the SAEG and HIN cores is about $4.12 \times 10^{-8} \pm 1.49 \times 10^{-8} \mathrm{~kg} / \mathrm{m}^{3}$ and $2.79 \times 10^{-8} \pm$ $1.9 \times 10^{-8} \mathrm{~kg} / \mathrm{m}^{3}$, respectively. Compared with the mean low-field susceptibility $(\chi)$ for the same set of samples $\left(5.5 \times 10^{-8} \pm 8.6 \times 10^{-9} \mathrm{~kg} / \mathrm{m}^{3}\right.$ and $4.44 \times 10^{-8} \pm 2.67 \times 10^{-8} \mathrm{~kg} / \mathrm{m}^{3}$, respectively) it is evident that $\chi_{\text {HiField }}$ accounts for about $70 \%$ of $\chi$ on average. It is not possible to estimate how much of $\chi_{\text {HiField }}$ originates from paramagnetic and how much from superparamagnetic (SP) minerals.

An anhysteretic remanent magnetization (ARM) was acquired in all samples using a dc bias field of $50 \mu \mathrm{T}$ and a maximum ac field of
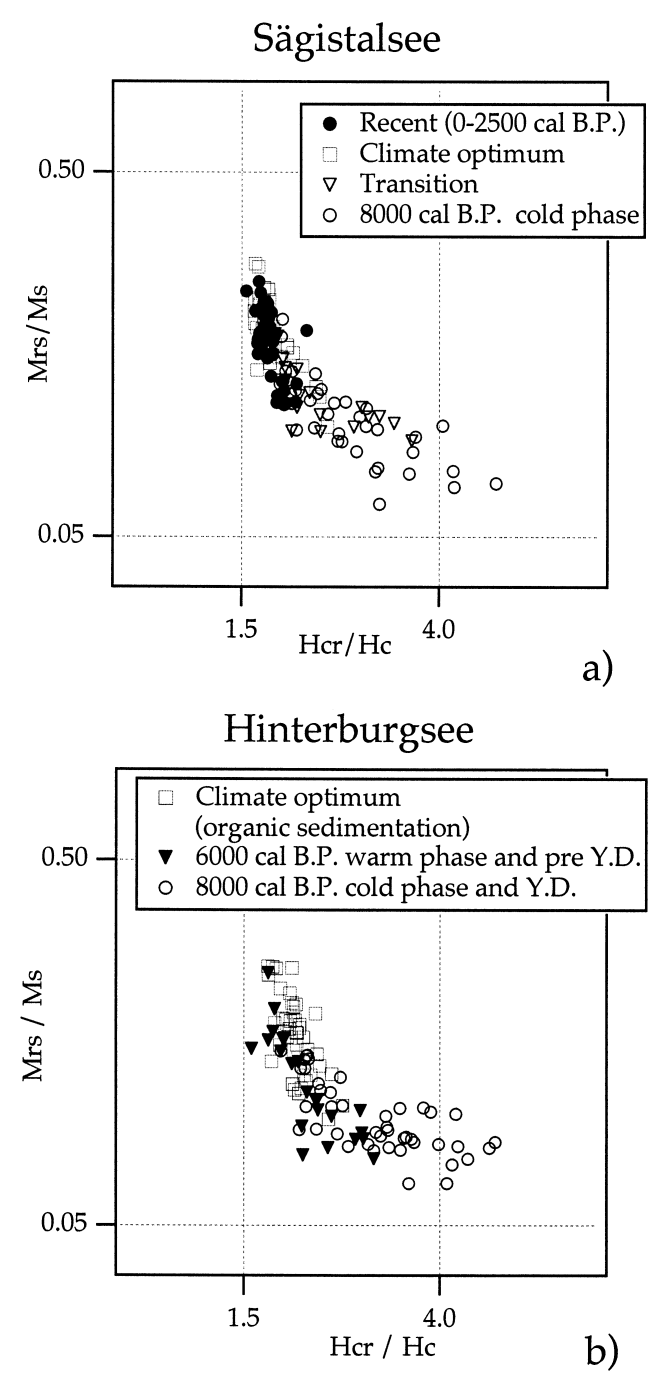

Fig. 7. Hysteresis parameters computed after the removal of the paramagnetic component of the magnetization. Parameters plotted with different symbols correspond to different core depths and are interpreted as climatic stages or changes in sedimentation style.

$100 \mathrm{mT}$. The ARM correlates very well with the IRM acquired at the similar field of $150 \mathrm{mT}$ in both the SAEG and HIN cores (Fig. 8a,b), indicating a uniform ARM/IRM ratio that suggests a uniform grain size of the low-coercivity mineral along the whole cores. An excellent estimate of 
Sägistalsee

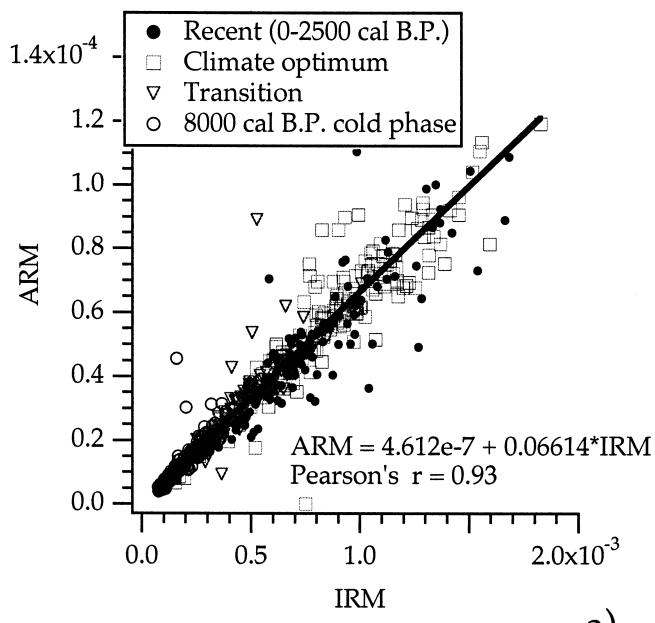

a)

\section{Hinterburgsee}

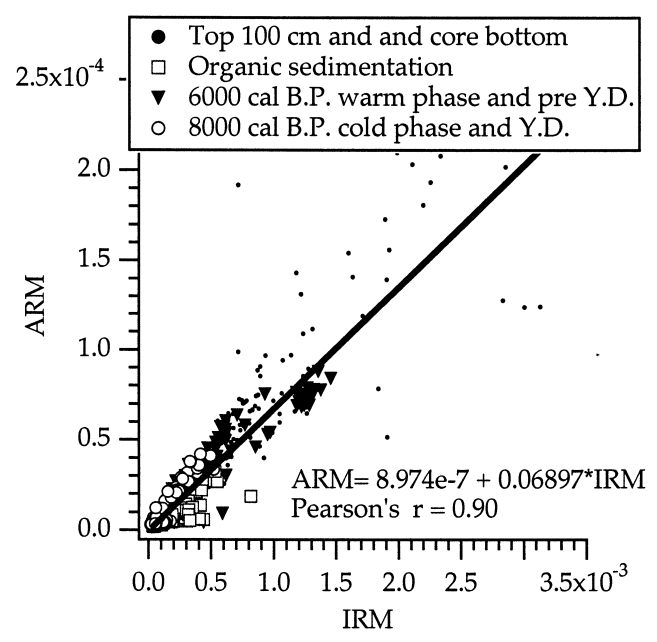

b)

Fig. 8. Scatter plot of ARM versus IRM. In both the plots the ARM was acquired with a de field of $50 \mu \mathrm{T}$ and a maximum ac field of $100 \mathrm{mT}$, the IRM was acquired in a field of $150 \mathrm{mT}$. ARM and IRM magnetization are in mass units (A $\mathrm{m}^{2} / \mathrm{kg}$ ). Data are plotted with different symbols corresponding to different climatic stages or sedimentation styles. The mean value of the ARM/IRM ratio is given by the slope of the best-fit line.

the mean ratio ARM/IRM is given by the slope of the best-fit line, which is practically identical in the two sites (Fig. 8a,b) and emphasizes similar magnetic properties within different lakes.

\section{Variation of magnetic parameters with depth}

The low-field susceptibility $(\chi)$, ARM and IRM (acquired in a field of $1 \mathrm{~T}$ ) are plotted against depth in Figs. 9 and 10, respectively, for the SAEG and HIN cores. In these and subsequent plots the data have been smoothed to reduce the high frequency variations using a five point Gaussian filter [25].

The ARM and the IRM correlate very well in both cores and their intensity is generally larger during the warm stages, indicating a higher concentration of ferrimagnetic minerals. The remanent magnetization in SAEG is low at the core bottom, then increases in the middle part of the core (above $800 \mathrm{~cm}$ ) and decreases slightly again near the core top (Fig. 9). In the HIN core, the ARM and the IRM are low during the Younger Dryas stage (1000-1200 cm depth) and the 7500 9000 cal BP cooler phase at about $600 \mathrm{~cm}$ depth (Fig. 10). A major decrease in ARM, IRM and $\chi$ occurs at about $450 \mathrm{~cm}$ depth with the onset of the organic sedimentation. In both lakes, the low-field susceptibility is roughly parallel to the IRM (Fig. 9b), although they do not correlate very well in detail presumably because of the large influence of the paramagnetic and possibly SP minerals.

Following Lanci et al. [13], we use the ratio of the isothermal magnetization acquired in fields of $150 \mathrm{mT}$ and $1 \mathrm{~T}\left(\mathrm{IRM}_{0.15 \mathrm{~T}} / \mathrm{IRM}_{1 \mathrm{~T}}\right)$, hereafter called $c$-ratio as a measure of the amount of high-coercivity minerals in the sediments. Values of the $c$-ratio are close to 1 when virtually no high-coercivity mineral is present, while lower values mean a higher content of high-coercivity minerals. For practical reasons we used the backfield magnetization instead of the direct magnetization with a field of $150 \mathrm{mT}$ in the samples from the HIN core. We also use the ratio of magnetization acquired at room temperature $(290 \mathrm{~K})$ and liquid nitrogen temperature $(77 \mathrm{~K})\left(\mathrm{IRM}_{290 \mathrm{~K}} / \mathrm{IRM}_{77 \mathrm{~K}}\right)$ in a field of $150 \mathrm{mT}$, hereafter called the $t$-ratio as an estimate of the content of SP minerals. The accuracy of this technique was tested in the Bachalpsee sediments [13] where the presence of SP grains was investigated with precise low-temperature measurements. Values close to 1 indicate no 


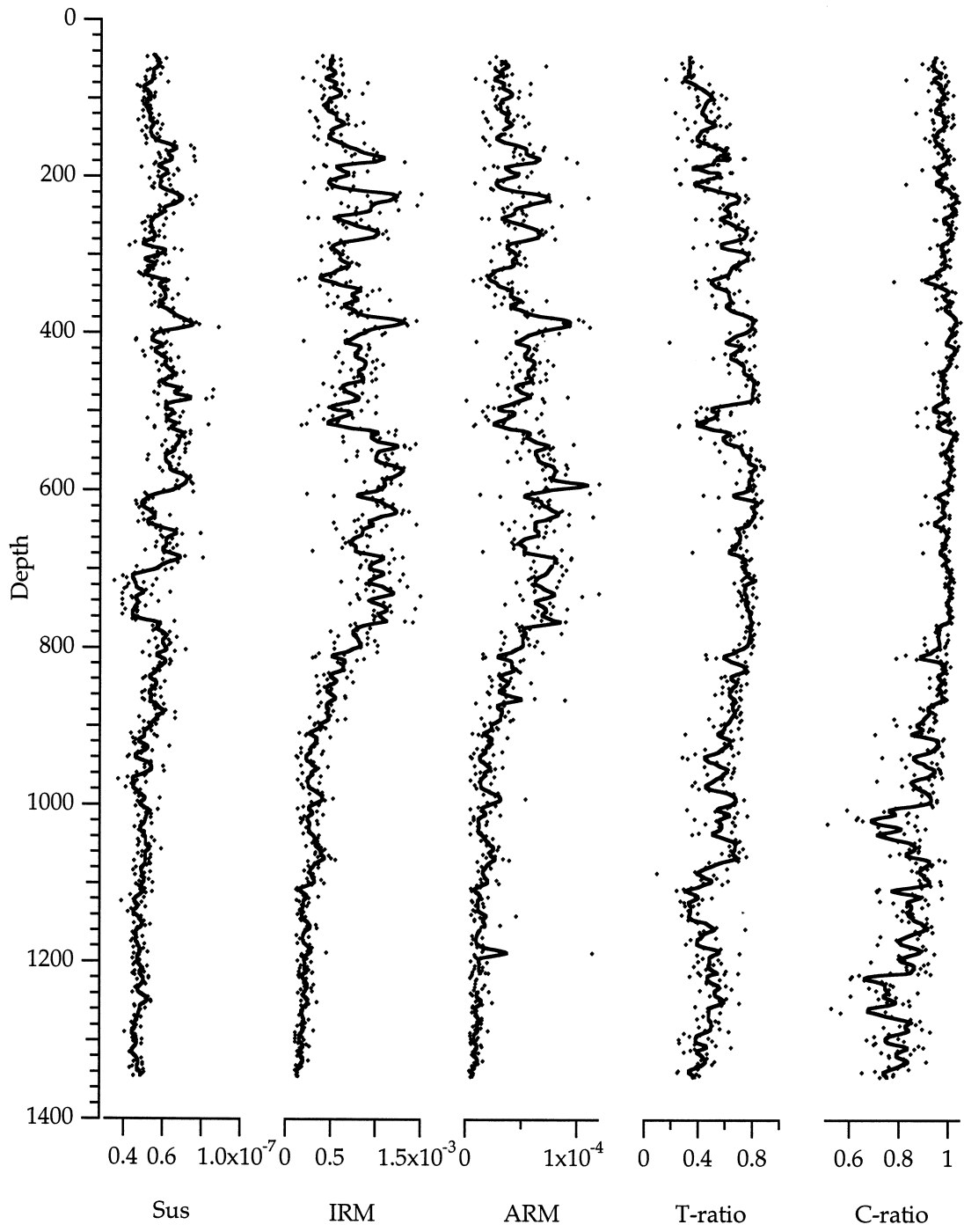

Fig. 9. Sediment magnetic properties of the SAEG core plotted versus core depth in $\mathrm{cm}$ below the surface. The ARM is acquired with a dc field of $50 \mu \mathrm{T}$ and a maximum ac field of $100 \mathrm{mT}$, and the IRM is acquired in a field of $1 \mathrm{~T}$. The low-field susceptibility and the magnetization are in mass units $\left(\mathrm{m}^{3} / \mathrm{kg}\right.$ and $\mathrm{A} \mathrm{m}^{2} / \mathrm{kg}$, respectively), the $c$-ratio and $t$-ratio (i.e. IRM $_{0.15 T} / \mathrm{IRM}_{1 T}$ and $\left.\mathrm{IRM}_{290 K} / \mathrm{IRM}_{77 K}\right)$ are dimensionless. The minimum at about $500 \mathrm{~cm}$ depth in the $t$-ratio is due to a forest fire. Smoothed signals are plotted with a continuous line and the actual measurements are plotted with markers in this and subsequent figures.

SP minerals and lower values mean a higher content of SP minerals. The low-temperature IRM was acquired after the samples had been cooled down to the liquid nitrogen temperature $(77 \mathrm{~K})$ in a magnetically shielded space to avoid the acquisition of low-temperature TRM. During the whole process the samples were kept in liquid nitrogen, and particular care was taken during the magnetization and the measurement to avoid any significant re-heating of the samples.

In the SAEG core the $c$-ratio is low in the core bottom and increases upward, indicating a decrease of the high-coercivity magnetic minerals above approximately $800 \mathrm{~cm}$ depth. The $t$-ratio is roughly parallel to the $c$-ratio in the lower part of the core, suggesting a decrease in the con- 


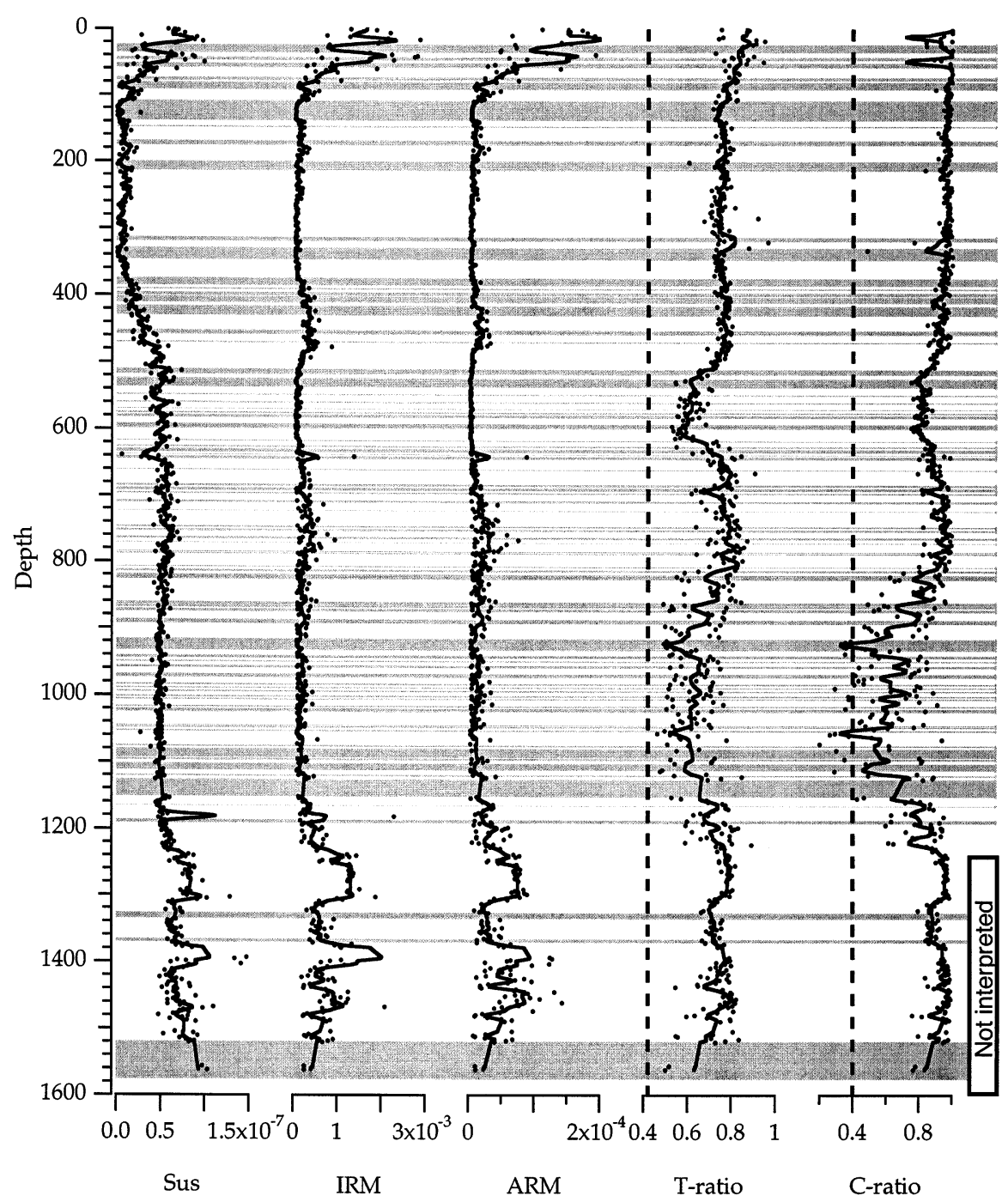

Fig. 10. Sediment magnetic properties of the HIN core plotted versus core depth, units are as in Fig. 9. The horizontal gray bands represent turbidites or slump deposits that were removed when calculating the depth-age model. Vertical dashed lines in the $c$-ratio and $t$-ratio plots are the average values of samples from the catchment, which are interpreted as characteristic of the detrital input.

centration of SP minerals upcore from the bottom. In the upper part of the core, the $t$-ratio decreases again in a more pronounced fashion than the $c$-ratio, although most of the peaks in the two records can be correlated along the whole core. The large peak in the $t$-ratio at $500 \mathrm{~cm}$ depth in the SAEG corresponds to significant charcoal matter in the sediment. It is associated with deforestation and burning from Bronze-Age settle- ments and therefore it is not interpreted climatically. In the HIN core both the $c$-ratio and $t$-ratio are low around $1000 \mathrm{~cm}$ depth, corresponding to the Younger Dryas, and to a smaller extent between 500 and $600 \mathrm{~cm}$. There are no significant variations of the ratios between 450 and $100 \mathrm{~cm}$; above $100 \mathrm{~cm}$ the anthropogenic activities (cattle grazing) have altered the sedimentation process.

A set of 39 samples taken from the bedrock and 
Table 2

Mean value and standard deviation of rock-magnetic parameters of samples from the HIN catchment

\begin{tabular}{lll}
\hline Data & Mean value & $N$ \\
\hline$\chi\left(\mathrm{m}^{3} / \mathrm{kg}\right)$ & $6.40 \times 10^{-8} \pm 1.92 \times 10^{-8}$ & 39 \\
$\mathrm{ARM}\left(\mathrm{A} \mathrm{m}^{2} / \mathrm{kg}\right)$ & $1.84 \times 10^{-5} \pm 8.81 \times 10^{-6}$ & 39 \\
$\left.\mathrm{IRM}_{1 \mathrm{~T}}(\mathrm{~A} \mathrm{~m})^{2} / \mathrm{kg}\right)$ & $1.75 \times 10^{-4} \pm 7.33 \times 10^{-5}$ & 28 \\
$c$-ratio & $0.40 \pm 0.24$ & 28 \\
$t$-ratio & $0.42 \pm 0.10$ & 28 \\
\hline
\end{tabular}

soils in the catchment area of the HIN were measured to gather information on the magnetic properties of the detrital fraction. In fact we assume that they represent a purely detrital sediment component. The average results are listed in Table 2 using the same magnetic parameters used in the core. The content of SP minerals in these samples was also investigated using the frequency dependent susceptibility $\left(\chi_{\mathrm{fd}}\right)$ measured with the dual frequency Bartington meter. The mean $\chi_{\mathrm{fd}}$ values of different groups of samples are listed in Table 3 . No samples could be collected from the SAEG catchment.

\section{Discussion}

\subsection{Climatic interpretation of the rock magnetic record}

The general environment in the catchment areas of the SAEG and in HIN is quite similar to that of the previously studied Bachalpsee [13]. The main differences between these sites are the altitude, that influences the vegetation, and the bedrock lithology. The SAEG is located slightly above the present tree line, although plant macrofossils suggest that trees were present in the catchment during the Holocene. The HIN, on the other hand, is located well below the current tree line. At this site the development of the forest during warm stages and their retreat during the cold stages probably had some influence on the sedimentation that will be discussed later.

The sparse vegetation in the SAEG catchment does not seem to have any perceptible influence on the sediment magnetic properties. The mag- netic properties of the sediments are very similar to those of the Holocene section of the Bachalpsee in terms of concentration (i.e., ARM and IRM intensity), mineralogy and hysteresis parameters (Table 1). Therefore the magnetic record is interpreted using the same criteria used on the Bachalpsee core [13]. In our interpretation, high values of the $c$-ratio and $t$-ratio correspond to warm stages and low values to cold stages, which is in good general agreement with the biological data. The IRM intensity, indicating the concentration of ferromagnetic minerals, is another climatically sensitive parameter that has largely increased during the warm stages. The shape of hysteresis loops (Fig. 6) is consistent with the magnetic mineral interpretation and the Day parameters conform to the results and climatic interpretation in the previously studied Bachalpsee. Compared to the Bachalpsee, however, in the SAEG record the cold stage magnetic mineral assemblage (which is, in our interpretation, the most detrital) has a smaller content of high-coercivity minerals and a higher content of SP minerals. Since in the Bachalpsee the high-coercivity minerals are found to be detrital, this difference can be explained as being caused by the different bedrock lithology. The catchment area of the Bachalpsee consists of shales with some limestone units from the Dogger formation, whereas limestones from the Malm formation characterize the catchment area of SAEG. Possibly as a consequence of these local differences the amplitude of the $c$-ratio and $t$-ratio response to climate changes are different.

In the HIN core the average magnetic properties of the Holocene section are very similar to those of the Bachalpsee and SAEG cores (see Table 1). Moreover, in the HIN the core bottom reaches the Younger Dryas cold stage (Fig. 2b), and we were able to use samples taken from this and from the subsequent warm stage (Preboreal) to verify the changes of magnetic properties predicted from the Bachalpsee site. The samples taken from the Younger Dryas age are characterized by a significant contribution of high-coercivity minerals as deduced from the IRM acquisition curves (Fig. 5). On the other hand, samples taken from the Holocene section have a higher IRM intensity and the IRM acquisition curves saturate 
Table 3

Mean value and standard deviations of the frequency dependent susceptibility $\left(\chi_{\mathrm{fd}}\right)$ of samples from the HIN catchment

\begin{tabular}{llr}
\hline Sample & $\begin{array}{l}\chi_{\mathrm{fd}} \\
(\%)\end{array}$ & $N$ \\
\hline Soil (organic) & $4.76 \pm 3.88$ & 10 \\
Regolith & $9.73 \pm 2.38$ & 7 \\
Bedrock (shale) & $9.43 \pm 1.20$ & 5 \\
Bedrock (limestone) & $13.89 \pm 4.61$ & 4 \\
Near-shore sediment & $9.69 \pm 3.10$ & 13 \\
Overall & $9.10 \pm 3.89$ & 39 \\
\hline
\end{tabular}

at about 150-200 $\mathrm{mT}$, showing no sign of highcoercivity minerals. The hysteresis loops (Fig. 6) conform to the interpretation of the magnetic mineralogy, and the hysteresis parameters show a clear clustering of warm and cold samples (Fig. 7) as also found in the other Alpine sites. Detailed low-temperature measurements are not available for the HIN samples, nevertheless the $t$-ratio and the $c$-ratio parallel each other, suggesting that the SP content is also climate controlled. The magnetic results from HIN are consistent with that of SAEG and Bachalpsee, and are therefore interpreted in the same way.

The mean magnetic properties of catchment samples (see Table 2) compared with those from the HIN core indicate that the detrital magnetic signal is very similar to that of the cold periods in the core in both concentration (IRM and ARM), coercivity ( $c$-ratio) and SP content ( $t$-ratio). The $\chi_{\mathrm{fd}}$ measurements confirm the relatively high content of SP minerals. The lower values of $\chi_{\mathrm{fd}}$ measured in the organic-rich soil compared to the higher values found in the regolith and bedrock samples (Table 3) show that the SP minerals in the catchment samples are not produced in the poorly developed soils but are characteristic of the bedrock. This is in agreement with the results from Bachalpsee. The low IRM and ARM intensity in the detrital fraction indicates that the more abundant magnetite concentration found in the core during warm periods must have a different origin. Since the larger concentrations cannot be a consequence of the detrital input (which is also likely to be smaller during the warm periods) the increase in IRM intensity in this and other studied Alpine lakes is interpreted as resulting from a magnetic mineral of authigenic origin.

In the HIN the content of organic matter in the sediment is greatly increased as the sedimentation changes from clastic to organic at about $450 \mathrm{~cm}$ depth (corresponding to the age of $7500 \mathrm{cal} \mathrm{BP}$ ). The onset of dense vegetation and the development of soil can explain the change in sedimentation type. At the same time the vegetation can effectively reduce the erosion in the catchment and thus the sedimentation rate in the lake as indicated by the depth-age model. The concentration of magnetic minerals is lower during the interval of organic sedimentation (Fig. 10). The low values of ARM, IRM and susceptibility could be interpreted as a consequence of magnetite dissolution due to reducing condition in the anoxic sediment [26,27]. An alternative explanation is that the production of authigenic magnetite is reduced in an anoxic environment. In either case this effect completely obliterates the climatic signal recorded in the sediment magnetism, and we restrict our interpretation to the section of core between the lower recovery gap at $1280 \mathrm{~cm}$ and the beginning of organic sedimentation at $450 \mathrm{~cm}$ depth. This section of the HIN core, corresponding approximately to $7500-12000 \mathrm{cal} \mathrm{BP}$, gives us a detailed record of the last deglaciation in the Alpine region.

A sudden increase in the concentration of the magnetic minerals is observed in the upper $100 \mathrm{~cm}$

Table 4

Principal component analysis

\begin{tabular}{lllll}
\hline & Sägistalsee & \multicolumn{3}{l}{ Hinterburgsee } \\
\hline Principal components & $4.067 \times 10^{-1}$ & $-9.136 \times 10^{-1}$ & $9.066 \times 10^{-1}$ & $-4.220 \times 10^{-1}$ \\
& $9.136 \times 10^{-1}$ & $4.067 \times 10^{-1}$ & $4.220 \times 10^{-1}$ & $9.066 \times 10^{-1} 1$ \\
Eigenvalues & $3.943 \times 10^{-2}$ & $3.423 \times 10^{-3}$ & $3.081 \times 10^{-2}$ & $3.246 \times 10^{-3}$ \\
Explained variance (\%) & 92.0 & 8.0 & 90.5 & 9.5 \\
\hline
\end{tabular}


of the core, corresponding approximately to the last $1000 \mathrm{yr}$. It is suggested that an erosive phase took place in the catchment that interrupted the organic sedimentation, therefore the magnetite dissolution. This phase is associated with deforestation and grazing, as indicated by an increase of Alpine herb pollen and it is interpreted as evidence for human impact.

\subsection{Comparison of the Alpine lake records}

The records from SAEG, HIN and the previously studied Bachalpsee are expected to give a comparable picture of the climate change in the Alpine region. Therefore, we compare a climate proxy derived from the magnetic measurements in the three lakes on a common time scale derived from the described depth-age models. Although sensitive to different properties (the hematite and SP content) the $c$-ratio and $t$-ratio are assumed to have a nearly identical response to climate, therefore we reduce them to a single proxy. The $c$-ratio and the $t$-ratio are reduced to a single data using the principal component analysis (PCA) (e.g. [28]). This technique is able to extract the part of signals that have a common variability (covariance) and discard the other, which is possibly due to noise, giving a more significant climate proxy. PCA was computed using the nonsmoothed data of the $c$-ratio and $t$-ratio in each core without any normalization since the ratios vary naturally between 0 and 1 . The principal components (i.e., eigenvectors of the covariance matrix), their eigenvalues and the explained variance are shown in Table 4. The first PCA component can account for more than $90 \%$ of the variance of the $c$-ratio and $t$-ratios validating their very good visual correlation. The first PCA component is therefore taken as our 'best' climate proxy.

Some further processing was necessary in order to compare directly the three records on the same time scale. The main PCA components were interpolated to evenly space time intervals based on the respective depth-age models, and finally the high frequency signal was filtered out using a lowpass, second-order Butterworth filter with a cutoff frequency of $200 \mathrm{yr}$. The reason for filtering was to minimize the effect of the different sampling densities in the different cores as well as in different sections within the same core, caused by variable sedimentation rates. The filtered principal PCA component from the SAEG, HIN and Bachalpsee core are compared in Fig. 11. The part of the HIN record above $450 \mathrm{~cm}$ and below $1280 \mathrm{~cm}$ depth was discarded as explained above.

The three cores record the same general climate variation and some finer scale variations can also

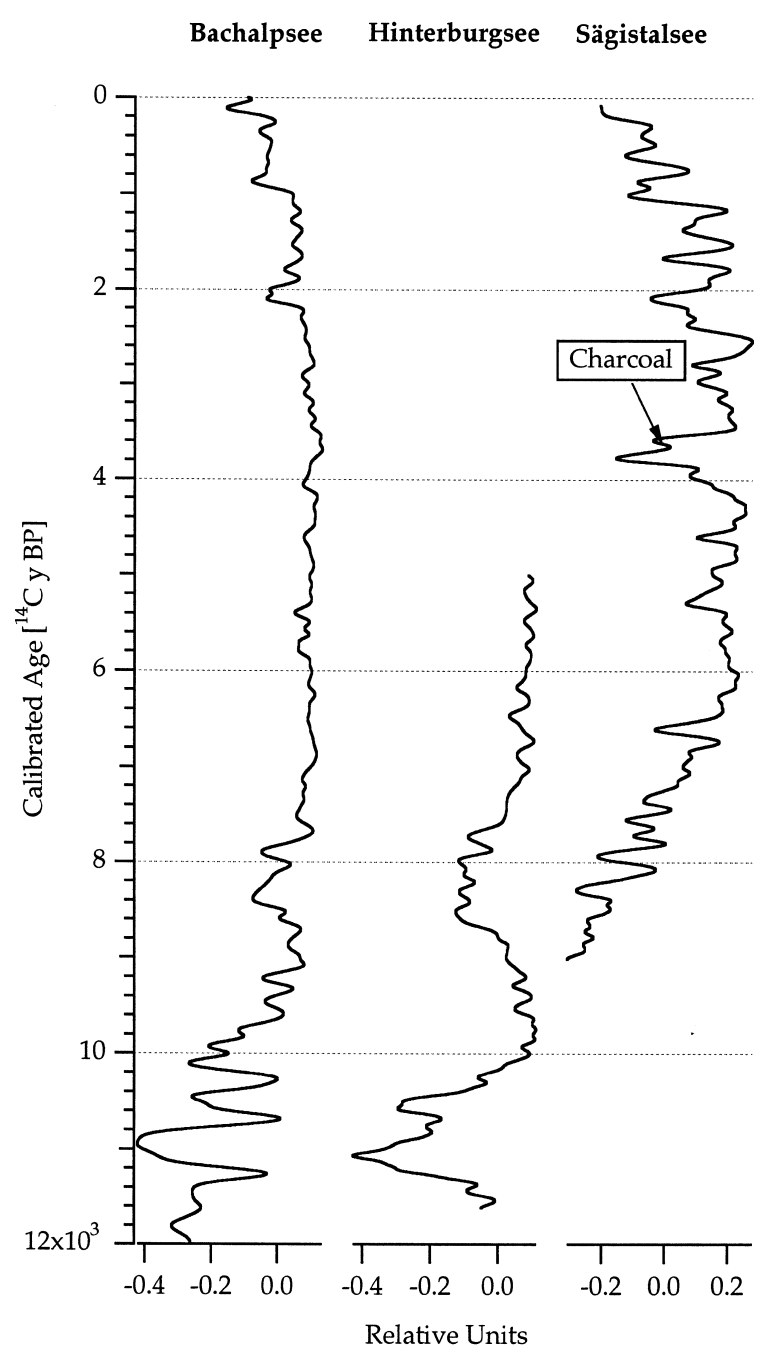

Fig. 11. Magnetic climate proxies from the Alpine lake cores plotted versus calibrated ${ }^{14} \mathrm{C}$ age (cal BP). The Bachalpsee data are from [13]. Low values of the PCA relative units indicate a cooler climate and high values indicate a warmer climate. 
be correlated. The ages in the Bachalpsee core older than 8300 cal BP and in the HIN core older than 10000 cal BP are based solely on a level having similar pollen assemblages. Although its absolute age may not be well defined, this level marks an event that is coeval in the whole region and therefore can be appropriately used in correlating the records from Bachalpsee and HIN. This relatively poor dating at the core bottom can explain the less than perfect match of the two records during the Younger Dryas. Different amplitudes in the response to the same climatic fluctuation can be observed comparing the SAEG to the Bachalpsee record. This may provide insight into the site dependency of this climate proxy and suggests a non-linear response.

\section{Conclusions}

The response of the magnetic properties of sediments to climate changes in the three different Alpine lakes is remarkably uniform and not strongly influenced by differences between sites. We have found that the $t$-ratio, indicating the content of SP grains and, the $c$-ratio, indicating the contribution of hematite, are the parameters that best represent the environmental processes. The choice of our climate proxy was based on the distinct characteristic of these Alpine lakes, particularly the presence of hematite and SP grains in the catchment bedrock, authigenesis, lack of magnetic sulphides and minimal human impact. Although quite constant in the studied sites, these characteristic are certainly not universal and their use should not be generalized elsewhere.

The effect of climate on the sediment magnetic properties in this particular environment is mainly a consequence of the erosion in the catchment basin (hence the influx of heterogeneous detrital sediments in the lake) and the formation of authigenic magnetic mineral with remarkably uniform magnetic properties, identified as magnetite by IRM acquisition and thermal demagnetization. The properties of detrital sediments are a high concentration of hematite, identified by IRM ac- quisition and thermal demagnetization, and SP grains, identified by low-temperature IRM and frequency dependent susceptibility. These characteristics are found to be controlled mainly by the bedrock magnetic properties. Authigenic magnetite is found during warm and humid climate stages if the anoxic conditions in the sediments are not too severe. In such a case authigenesis seems to be the main factor controlling the concentration of magnetite. Biogenic bacterial magnetite is likely to be produced in lake environments [29-31], nevertheless chemical formation is also possible. Direct evidence such as observation of magnetosomes would be required to confirm the bacterial hypothesis.

In the studied Alpine lakes the organic sedimentation is a disturbing factor in the magnetic record of climate changes. When it becomes too large it can strongly reduce the concentration of the authigenic magnetite and completely destroy the climatic signal. This effect was observed in the upper part of the HIN core from 100 to $450 \mathrm{~cm}$ depth. Therefore the best results are obtained in the sites at the highest elevation where little or no vegetation is present in the catchment area. For the same reasons these results cannot be applied to lakes with a high degree of anoxia. Forest fires may represent another important source of noise in the climatic signal as in the SAEG core at about $500 \mathrm{~cm}$ depth. They can usually be identified, and thus removed, due to the 'spiky' nature of the signal and the presence of charcoal in the sediments.

Although we have found that the concentration of ferrimagnetic mineral is clearly enhanced during the warm and humid stages in all the Alpine sites, neither the ARM, the IRM nor the susceptibility are found to be the best climate proxy. The $t$-ratio and the $c$-ratio can mediate between detrital minerals transported to the lake and authigenically produced ferromagnetic minerals giving a smoother and possibly more linear parameter. The $t$-ratio and the $c$-ratio usually parallel one another but they can be combined and reduced to a unique and more reliable parameter using the PCA. The hysteresis loops were not extensively used in this study, but they have shown a good potential to discriminate uniform authigenic mag- 
netite, characteristic of the warm stage, from the magnetically more heterogeneous detrital input.

\section{Acknowledgements}

We would like to thank Pierre Rochette from the University of Marseille and Dennis V. Kent from the Lamont-Doherty paleomagnetic laboratory for use of their Micromag magnetometers for hysteresis measurements. The manuscript benefited greatly from reviews by Frank Oldfield and John Dearing. We also thank Dennis V. Kent, Karin Koinig and Oliver Heiri for their useful comments and discussion. Contribution No. 1163, Institute of Geophysics, ETH-Zürich.[R $\boldsymbol{V}]$

\section{References}

[1] B. Ammann, A.F. Lotter, Late-glacial radiocarbon and palynostratigraphy on the Swiss plateau, Boreas 18 (1989) 109-126.

[2] B. Ammann, M.J. Gaillard, A.F. Lotter, Switzerland, in: B.E. Berglund, H.J.B. Birks, M. Ralska-Jasiewiczowa, H.E. Wright (Eds.), Palaeoecological Events during the last 15000 years: Regional Syntheses of Palaeoecological Studies of Lakes and Mires in Europe, Wiley, Chichester, 1996, pp. 647-666.

[3] L. Wick, W. Tinner, Vegetation changes and timberline fluctuations in the central Alps as indicators of Holocene climatic oscillations, Arct. Alp. Res. 29 (1997) 445-458.

[4] A.F. Lotter, B. Ammann, M. Sturm, Rates of changes and chronological problem during the late-glacial period, Clim. Dyn. 6 (1992) 233-239.

[5] B. Ammann, Response times in bio- and isotopes-stratigraphy to late-glacial climatic shift: an example from lake deposits, Eclogae Geol. Helv. 82 (1989) 183-190.

[6] B. Ammann, Litho- and palynostratigraphy at Lobigensee: evidence for trophic changes during the Holocene, Hydrobiologia 143 (1986) 301-307.

[7] J. Bloemendal, F. Oldfield, R. Thompson, Magnetic measurements used to access sediment influx at llyn goddionduon, Nature 280 (1979) 50-53.

[8] T.E. Evans, F. Heller, Magnetic enhancement and paleoclimate: study of a loess/paleosol couplet across the loess plateau of China, Geophys. J. Int. 117 (1994) 257-264.

[9] L. Lanci, W. Lowrie, F.C. Wezel, Magnetic properties of Pleistocene sediments from Tyrrenian sea: a correlation with paleoclimatic record, Terra Nova 7 (1995) 535-543.

[10] K.L. Verosub, A.P. Roberts, Environmental magnetism: past, present and future, J. Geophys. Res. 100 (1995) 2175-2192.
[11] F. Heller, M.E. Evans, Loess magnetism, Rev. Geophys. 33 (1995) 211-240.

[12] B.A. Maher, R. Thompson, Quaternary Climates, Environments and Magnetism, University Press, Cambridge, 1999.

[13] L. Lanci, A.M. Hirt, W. Lowrie, A.F. Lotter, G. Lemke, M. Sturm, Mineral-magnetic record of late quaternary climatic changes in a high Alpine lake, Earth Planet. Sci. Lett. 170 (1999) 49-59.

[14] A.F. Lotter, B. Ammann, H.J.B. Birks, O. Heiri, A. Hirt, L. Lanci, G. Lemcke, M. Sturm, J. van Leeuwen, I.R. Walker, L. Wick, Aquareal: a multi-proxy study of Holocene sediment archives in Alpine lakes, Würzbg. Geogr. Manuskr. 41 (1997) 127-128.

[15] J. Merkt, H. Streif, Stechrohr-bohrgeräte für limnische und marine lockersedimente, Geol. Jb. 88 (1970) 137-148.

[16] A.F. Lotter, H.J.B. Birks, Holocene sediments of Sgistalsee, a small lake at the present-day tree line in the Swiss Alps, J. Paleolimnol. (2001), in press.

[17] O. Heiri, A.F. Lotter, 4000 years of human impact on the chironomid population of an Alpine lake: sensitivity of the community to disturbance and resilience of the ecosystem, J. Paleolimnol. (2001), in press.

[18] W.O. van der Knaap, L.J. Wick, F.N. van Leeuwen, A.F. Lotter, Holocene vegetation development in the catchment of Sgistalsee (1935 m asl), a small lake in the Swiss Alps, J. Paleolimnol. (2001), in press.

[19] A.F. Lotter, C. Ohlendorf, K.A. Koinig, W. Shotyk, M. Sturm, 9000 years of lithogenic major and trace elements in Alpine lake sediments, J. Paleolimnol. (2001), in press.

[20] A.M. Hirt, L. Lanci, K. Koinig, Mineral magnetic record of Holocene environmental changes in Sgistalsee, Switzerland, J. Paleolimnol. (2001), in press.

[21] C.J.F. ter Braak, Ordination, in: R.H.G. Jongman, C.J.F. ter Braak, O.F.R. van Tongeren (Eds.), Data Analysis in Community and Landscape Ecology, Pudoc, Wageningen, 1987, pp. 91-173.

[22] C.J.F. ter Braak, CANOCO: a FORTRAN Program for Canonical Community Ordination, Microcomputer Power, Ithaca, NY, 1987-1992.

[23] W. Lowrie, Identification of magnetic minerals in a rock by coercivity and unblocking temperature properties, Geophys. Res. Lett. 17 (1990) 159-162.

[24] R. Day, M. Fuller, V.A. Schmidt, Hysteresis properties of titanomagnetite: grain size and compositional dependence, Phys. Earth Planet. Inter. 13 (1977) 260-267.

[25] P. Marchand, L. Marmet, Binomial smoothing filter: a way to avoid some pitfalls of least-squares polynomial smoothing, Rev. Sci. Instrum. 54 (1983) 1034-1042.

[26] J. Hilton, J.P. Lishman, The effect of redox changes on the magnetic susceptibility of sediments from a seasonally anoxic lake, Limnol. Oceanogr. 30 (1985) 907-909.

[27] N.J. Anderson, B. Rippey, Diagenesis of magnetic minerals in the recent sediments of a eutrophic lake, Limnol. Oceanogr. 33 (1988) 1476-1492.

[28] D.F. Morrison, Multivariate Statistical Methods, 3rd edn., McGraw-Hill, New York, 1990. 
[29] D.G. Weiss, N. Petersen, H. Vali, Magnetic bacteria in lake sediments, in: F.J. Lowes, D.W. Collinson, J.H. Parry, S.K. Runcorn, D.C. Tozer, A. Soward (Eds.), Geomagnetism and Paleomagnetism, Kluwer Academic Press, Dordrecht, 1989, pp. 231-242.

[30] J.F. Stolz, D.R. Lovley, S.F. Haggerty, Biogenic magnetite and the magnetization of sediments, J. Geophys. Res. 95 (1990) 4355-4361.
[31] T.B. Hawthorne, J. McKenzie, Biogenic magnetite: authigenesis and diagenesis with changing redox conditions in Lake Greifen, Switzerland, in: D.M. Aissoui, D.F. McNeill, N.F. Hurlei (Eds.), Application of Paleomagnetism to Sedimentary Geology, SEPM Special Publication No. 49, Society for Sedimentary Geology, 1993. 